\title{
The Pharmacogenetics of Symptom Response to Antipsychotic Drugs
}

\author{
Gavin P Reynolds ${ }^{\bowtie}$ \\ Biomedical Research Centre, Sheffield Hallam University, Howard Street, Sheffield S1 1WB U.K.
}

\begin{abstract}
Antipsychotic drugs are limited in their efficacy by the relatively poor response of negative and cognitive symptoms of schizophrenia as well as by the substantial variability in response between patients. Pharmacogenetic studies have sought to identify the genetic factors that underlie the individual variability in response to treatment, with a past emphasis on dopamine and serotonin receptors as candidate genes. Few studies have separated effects on positive and negative symptoms, despite the established differences in response to drug treatment between these syndromes. Where this has been done most findings are consistent with the conclusion that dopamine receptor polymorphisms relate to positive symptom response, while negative symptom improvement is influenced by polymorphisms of genes involved in 5-HT neurotransmission. A wide range of polymorphisms in other candidate genes have been investigated, with some positive findings in those genes associated with glutamatergic transmission and/or risk factors for schizophrenia. However, there remains a lack of good replicated findings; furthermore there is little evidence to support drug-specific genetic associations with treatment response. While most past studies focused on single candidate genes, technology now permits genome-wide association studies with response to antipsychotics. Although not without major limitations, these "hypothesis-free" approaches are beginning to identify further important risk factors for treatment response. Again there is little consistency between various studies, although some of the polymorphisms identified are in genes involved in neurodevelopment, which is increasingly being recognized as important in the pathophysiology of schizophrenia.
\end{abstract}

Psychiatry Investig 2012;9:1-7

Key Words Polymorphisms, Genes, Schizophrenia, Negative symptoms, Positive symptoms.

\section{INTRODUCTION-CONCEPTS AND APPROACHES}

Severe mental illness represents a huge burden to society, reflecting the limited efficacy of current treatment for schizophrenia, bipolar disorder and major depressive disorder. The antipsychotic drugs, developed for the treatment of schizophrenia, are increasingly used for the treatment of mania in bipolar disorder, in which the evidence indicates they are the most effective therapy. ${ }^{1}$ They may also be used in treating a variety of behavioural problems associated with disorders from childhood to the elderly; in total well over $1 \%$ of the adult population now receive antipsychotic drug treatment. Wh-

Received: December 4, 2011 Revised: December 12, 2011

Accepted: December 12, 2011 Available online: January 9, 2012

$\triangle$ Correspondence: Gavin P Reynolds

Biomedical Research Centre, Sheffield Hallam University, Howard Street, Sheffield S1 1WB U.K.

Tel: +447740651500

E-mail: gavin.reynolds@hotmail.com

(a) This is an Open Access article distributed under the terms of the Creative Commons Attribution Non-Commercial License (http://creativecommons.org/licenses/bync/3.0) which permits unrestricted non-commercial use, distribution, and reproduction in any medium, provided the original work is properly cited. ile some people with schizophrenia respond well to antipsychotic drug treatment, a similar proportion (approximately one third) show little amelioration of their symptoms, while the remainder present varying degrees of symptom improvement. Treatment adherence is a frequently underestimated factor that contributes to this substantial variability and which can be influenced by the emergence of adverse drug effects, although patients taking their medication as prescribed can still show profound differences in response. There is little understanding of the underlying reasons for these individual differences, although accumulating evidence over the past 15 years indicates that genetic factors contribute substantially to the extent of symptom improvement following drug treatment.

Studies of siblings and twins have provided some evidence in support of genetics influencing the response to antipsychotic drugs. Thus symptom improvement following clozapine ${ }^{2}$ and olanzapine ${ }^{3}$ has shown strong concordance in monozygotic twin pairs. Identifying the genetic factors responsible for individual variability in the effects of drug treatment is the aim of pharmacogenetics. The pharmacogenetics of antipsychotic drugs has received substantial research effort over the 
past decade, driven by an awareness of the varied and often limited effectiveness of these drugs both in controlling symptoms of schizophrenia and in inducing adverse effects.

This review will address progress in the pharmacogenetics of antipsychotic response, an important target for study given the high proportion of patients in whom antipsychotic treatment is less that optimally effective. The inadequate response to treatment is more apparent in subgroups of symptoms; while antipsychotic drugs are often effective at controlling the positive psychotic symptoms, they are less able to ameliorate the negative and cognitive features of schizophrenia. These include social withdrawal, blunted mood, lack of self care and deficits in executive function and working memory which, along with depressed mood, are the symptoms that are most problematic in integrating the patient into society.

By far the great majority of pharmacogenetic studies of antipsychotic drug response have been performed in the context of schizophrenia, and the current review will be limited to this topic. It will not be a comprehensive listing of all pharmacogenetic results relating to individual differences in symptom response, but the major genes of interest will be mentioned, particularly where they have given rise to further pharmacogenetic study. Thus the review will aim to illustrate the current status of the field, with examples as well as reference to more specific review articles, primarily focusing on pharmacodynamic rather than pharmacokinetic influences on drug action.

Pharmacokinetic effects, such as genetic variation resulting in differences in activity in drug metabolising enzymes, can of course affect antipsychotic drug treatment by influencing plasma concentrations and availability to the brain, or by affecting the synthesis of active metabolites. These effects may to some extent be compensated for by titration to an effective dose. Such pharmacokinetic factors represent one level of pharmacogenetic influence; three further pharmacodynamic levels of pharmacogenetic associations can be identified depending on the nature of the gene-drug interaction. ${ }^{4}$ These influences include a) genes known or thought to be directly involved in the mechanisms of drug action, such as the dopamine D2 receptor, b) genes that may indirectly modify the primary drug mechanism, such as those involved in second messenger function or in interacting neurotransmitter systems and c) genes that are involved in disease pathology, such as dysbindin, or disease modification, such as catechol-O-methyltransferase (CO$\mathrm{MT}$ ), and which may therefore determine how responsive the disease may be to pharmacotherapy.

The starting point for pharmacogenetic investigation of treatment response, the phenotype, has in the past investigated variability in the DNA of one or a small number of "candidate" genes for study. Choice of candidate genes is hypothesis-driven, whereby genes are usually selected on the basis of their cod- ing for a protein that is known to be, or is potentially, involved in pharmacokinetic or pharmacodynamic aspects of drug action. Identification of sites of common DNA variation in these genes, primarily single nucleotide polymorphisms ("SNPs") or insertion/deletion sequences, provide the factors for association of genotype with phenotype.

Technological advance has resulted in the opportunity to investigate many (perhaps 1 million) SNPs across the whole genome and offer great power in identifying novel genetic associations unconstrained by prior hypotheses which, for the candidate gene approach, are inevitably founded on a limited understanding of the underlying mechanisms. These hypothesis-free genome-wide association studies (GWAS) are not without limitations; typically they select SNPs on the basis of position in the genome sequence, rather than as having known, or potential, functionality that may be chosen in candidate gene studies. They also have problems associated with the difficulties of data handling (where over $10^{9}$ individual results may be accumulated) and consequent statistical analysis and interpretation.

\section{CANDIDATE GENE STUDIES-FOCUS ON DOPAMINE AND SEROTONIN RECEPTORS}

It is generally considered that the primary antipsychotic mechanism involves antagonist action at dopamine D2 receptors in the brain. Thus polymorphisms in this gene (DRD2) have been widely investigated in respect of symptom response, as have the related D2-like receptor genes DRD3 and DRD4. Similarly, the 5-HT2A receptor is a major drug target proposed to differentiate the atypical antipsychotics from the older drugs.

The often inadequate effect of antipsychotic drugs on negative symptoms and cognitive deficits of schizophrenia, compared to the response of positive symptoms, has been emphasised above. However, the pharmacological mechanisms that might underlie antipsychotic drug effects on negative and cognitive symptoms are far from clear. It has been suggested that drug action at 5-HT2A receptors is also responsible for some improved efficacy of the atypical antipsychotics on negative symptoms, although the supporting evidence for this clinical effect is very limited, ${ }^{5}$ as is our understanding of the underlying mechanism. Nevertheless, there is some indication that 5-HT systems are involved in models of cognitive dysfunction in schizophrenia ${ }^{6,7}$ as well as in symptom amelioration by newer antipsychotic drugs, ${ }^{7}$ providing candidature in pharmacogenetic studies for HTR2A and other serotonergic genes such as HTR1A, HTR2C, HTR6 and HTT.

The first reports assessing genetic associations with antipsy- 
chotic treatment response inevitably concentrated on the most obvious candidate genes with some replicated, if not totally consistent, findings of polymorphisms in three receptors: dopamine D2, dopamine D3 and serotonin 5-HT2A, being associated with response to treatment (reviewed in 8,9 ). The association of the D2 receptor gene with response has been confirmed more recently in a systematic review, ${ }^{10}$ while overall association of the D3 gene remains weak and inconsistent (e.g. 11, 12). Other dopaminergic factors have been investigated in relation to drug response. The dopamine transporter (DAT) gene has shown both positive (with clozapine) and negative (with risperidone) association results, ${ }^{13,14}$ but there are no convincing findings indicating an influence of SNPs in the dopamine D1 or D4 receptors on treatment response.

A review of association studies with SNPs in the 5-HT2A receptor gene concluded that results indicate some weak association with antipsychotic response as well as with psychosis itself. ${ }^{15}$ Some further supporting data for the association with drug response has emerged from several more recent small studies including one employing the methodologically more rigorous transmission disequilibrium test. ${ }^{16}$ Nevertheless the effect is a small one and not consistently obtained. The same is true for genes for other markers of serotonergic function. The serotonin transporter (HTT), with what is perhaps the most studied polymorphism in psychiatry, the insertion/ deletion (ins/del) sequence in the promoter region, ${ }^{17}$ is associated with antipsychotic response in some (e.g. 18, 19) but not all $^{20}$ studies. A SNP in the 5-HT1A receptor gene has also been shown to have effects on the response to antipsychotic treatment. ${ }^{21-23}$ These HTT and HTR1A genes both code for proteins that control presynaptic activity of the serotonin neuron; the major SNPs investigated in each case appear to directly influence gene expression. Thus promoter sequence HTT SNPs including the ins/del polymorphism of HTT and the SNP found in the insertion sequence, ${ }^{24}$ influence HTT expression and activity, while the $-1019 \mathrm{C} / \mathrm{G}$ promoter SNP in HTR1A affects a transcription factor binding site, again influencing expression levels and their control of the 5-HT1A receptor, as well as being associated with suicide and diagnosis of depression. $^{25}$

\section{DIFFERENTIATING EFFECTS ON POSITIVE AND NEGATIVE SYNDROMES}

In developing the opportunities for genetic testing, it seems more valuable to differentiate groups of symptoms in terms of their response to treatment. As mentioned above, the negative features of the disease respond poorly to antipsychotic drugs and it is these, rather than the positive symptoms, that are more important in determining functional recovery in patients. A minority of outcome studies have assessed separately the responses of positive and negative symptoms to drug treatment, despite the established differences in the effects of antipsychotics on these symptom clusters. However, where this has been done, it appears that the majority of genes associated with positive symptom response are of dopamine receptors, while effects on negative symptoms are more associated with serotoninergic genes, in particular the 5-HT1A and 5-HT2A receptors. ${ }^{4}$ Updating these initial observations, more recent results confirm the general association of genetic polymorphisms in dopamine systems with changes in positive symptoms, and serotonin with negative symptoms, with notably few anomalies. Thus the previous finding of the association of negative symptom response has been confirmed for the HTR1A promoter SNP ${ }^{21,23}$ and identified for the HTT gene. ${ }^{26}$ An association with positive symptom response has been again confirmed for the ser9gly functional DRD3 $\mathrm{SNP}^{27}$ and intriguingly newly identified for the norepinephrine transporter gene. ${ }^{28}$ These results demonstrate relatively strong consistency, in spite of the substantial differences between samples in terms of treatment history (drug-naïve or previously-treated) and ethnicity.

These findings may seem surprising on first sight, given the variety of different genes involved. However this multiplicity of genetic factors points to common mechanistic pathways; for example, changes in the expression and activity of both 5-HT1A receptors and the 5-HT transporter are likely to affect serotonergic activity at the synapse, consequences of which may be mediated by post-synaptic receptors such as 5-HT2A. A similar but unconfirmed observation has been seen for another 5-HT receptor gene, $\mathrm{HTR}^{2} \mathrm{E}^{29}$; notably the results for COMT indicate association solely with negative symptom improvement (discussed below). Nevertheless the results strongly suggest that the catecholamine and serotonin neurotransmitter systems are implicated separately in drug response of the two syndromes, while the exact mechanisms of their involvement remain elusive. Certainly there is evidence that selective serotonin uptake inhibitors may be useful in the relief of negative symptoms in some patients. ${ }^{30}$

There are some other genetic associations with drug-induced changes in the more problematic negative and cognitive symptoms in schizophrenia. These include the val/met COMT polymorphism, ${ }^{31-33}$ which has a strong effect on enzyme activity and thereby influences dopamine (and norepinephrine) concentrations in the cortex where this enzyme, rather than neuronal transport, is primarily responsible for synaptic removal of catecholamine neurotransmitters. The glutamate metabotropic receptor-3 gene, a further risk factor for schizophrenia, has been reported as having SNPs associated with response, ${ }^{32}$ particularly of negative symptoms, ${ }^{34}$ although a fol- 
lowing study showed an association not with negative symptom response but with treatment-refractory schizophrenia. ${ }^{35}$ Dysbindin1, another gene with an established association with schizophrenia and implicated in neuronal and synaptic development as well as dopamine receptor function, also shows association with treatment response in refractory schizophrenia. ${ }^{36}$

Few other pharmacogenetic studies have specifically addressed positive symptom improvement, although many genetic associations with undifferentiated measures of symptom response may primarily reflect the generally greater improvement in positive symptoms. The latest and strongest single gene risk factor for schizophrenia, ZNF804A, is also reported to be associated with positive symptom response. ${ }^{37}$

In one study where a 5-HT1A gene SNP explained much of the variance in negative symptom response in first-episode patients, ${ }^{22}$ there was also an association with depressive symptom response, differentiated from that on negative symptoms. This is unsurprising, given the established association of this SNP with depression ${ }^{25}$ and its treatment..$^{38}$ An association with depression as well as negative symptoms has been found for the 5-HT transporter gene in patients receiving antipsychotics, although the influence of treatment on this finding was not determined. ${ }^{39}$ However it is notable that few pharmacogenetic studies have investigated separately the depression syndrome in schizophrenia, although it is an important determinant of relapse in patients receiving antipsychotics. ${ }^{40}$

\section{CLOZAPINE RESPONSE}

The unique efficacy of clozapine in the treatment of otherwise non-responsive patients has resulted in clozapine being a prime target for pharmacogenetic investigation. Approximately $50 \%$ of patients not otherwise responding to antipsychotic drug treatment benefit from clozapine; much early work on antipsychotic pharmacogenetics addressed this problem. A pharmacological basis for its clinical efficacy remains elusive; among the receptor mechanisms implicated, in addition to the 5-HT2A receptor antagonism common to most atypical antipsychotics, are effects at alpha2 adrenoceptors, 5-HT1A receptors and dopamine D1 receptors, although no single receptor action is likely to explain clozapine's action in full. ${ }^{41}$

In some early work Arranz et al. ${ }^{42}$ studied a range of candidate genes, primarily chosen on the basis of the known pharmacology of clozapine. They looked for association of response with 19 polymorphisms in 10 genes associated with monoamine neurotransmission; six polymorphisms together gave a (retrospective) sensitivity of $96 \%$ in identifying clozapine responders. The strongest components in this profile of polymorphisms were two SNPs in the HTR2A gene: one synonymous (silent) 102T/C in linkage disequilibrium with a promoter SNP $(-1438 \mathrm{~A} / \mathrm{G})$ with functional activity ${ }^{43}$ and one nonsynonymous his 452 tyr. These findings have not been consistently replicated ${ }^{9}$ but they nevertheless led to the establishment of a pharmacogenetic test for clozapine response, although this is no longer available. A confirmatory prospective trial to assess the predictability and value in practice of such pharmacogenetic testing for drug response has yet to be undertaken. Reflecting our incomplete understanding of the mechanism of clozapine's action, a consistent pharmacogenetic finding that might relate selectively to clozapine response still eludes us. Many pharmacogenetic studies, including several cited in this chapter, have been carried out on cohorts of clozapine-treated subjects as well as those receiving other antipsychotic drugs, ${ }^{44}$ but as yet there is no reliable evidence for distinct clozapine-specific pharmacogenetic associations with response.

\section{OTHER GENETIC ASSOCIATIONS WITH RESPONSE - CANDIDATE GENES TO GWAS}

The positive and replicated findings with SNPs in dopamine and serotonin genes, reviewed more extensively elsewhere, ${ }^{45}$ are reassuring in terms of our very limited understanding of pharmacological mechanisms. However they are are strongly influenced by a research bias towards testing these more obvious hypotheses and unfortunately do not consistently emerge from GWAS, as discussed below. Variation in these genes can usually only explain a small percentage of the variance in response, and further factors inevitably contribute to antipsychotic-induced improvement in symptoms. Those other genetic factors might include SNPs in a wide variety, perhaps many hundreds, of genes potentially influencing neuronal function, including other neurotransmitter receptors, enzymes and transporters, as well as second messenger systems or signalling pathways. Just one of many examples is the SNP in the G-protein beta3 subunit gene (GNB3), involved in receptor signal transduction, and which reportedly shows weak association with symptom response to antipsychotic treatment. ${ }^{46-48}$ However, there are few associations with symptom response outside the genes involving dopamine and serotonin systems that have yet been consistently replicated.

The independent and influential CATIE trial of the relative effects of several antipsychotic drugs ${ }^{5}$ has been very valuable in provide a large set of data on the consequences of treatment of a carefully controlled and rigorously assessed sample of people with schizophrenia. Although it is not without limitations, pharmacogenetic studies from this trial are beginning to yield interesting and novel findings. 
An investigation of a large series of 118 candidate genes ${ }^{49}$ identified several significant associations with change in the Positive and Negative Syndrome Scale (PANSS) in the CATIE sample, the numbers of which were roughly in line with the expected false discovery rate (22 of 2769 SNPs reached significance at $p<0.01)$. Seven of the significant SNPs were in glutamate receptor genes, which might be of more interest were it not for the fact that such genes were represented by over 1000 of the SNPs studied. This choice of candidates clearly reflects the increasing evidence of the importance of glutamate neurotransmission in in the pathology of schizophrenia ${ }^{50}$ particularly in relation to cognitive dysfunction. ${ }^{51}$ Nevertheless the authors also identified significant association with SNPs on HTR2A, DRD3, the nicotinic receptor alpha ${ }^{7}$ subunit gene and the excitatory amino acid transporter 4 gene (SLC1A6), among other candidates. None of the significant findings clearly differentiated effects on positive and negative symptoms. In their investigation of association with cognitive outcomes, some interesting findings emerged, again with strong contributions from glutamate receptors but also identifying effects of genes for the 5-HT4 receptor and for a neuronal adenylate cyclase. $^{49}$

A GWAS study of the same sample has provided very different results, with the strongest effect on change in PANSS shown with a SNP in an inter-gene sequence on chromosome 4; other novel results close to the significance threshold were in ANKS1B, CNTNAP5 and TRPM1, all of which are potentially involved in neuronal development or neurotransmission. ${ }^{52}$ How exactly they might be involved in drug response is far from clear, however; certainly replication as candidate genes in other samples is needed. The same group has looked at neurocognition as an outcome measure of response in this series ${ }^{53}$ finding significance in several genes of which the top two are EHF (a transcription factor with little evidence for a neuronal role) and SLC26A9 (a chloride ion transporter). Interpretation of these findings is not straightforward, although more reassuring are the findings of (somewhat weaker) association with DRD2 and ANKS1B, the latter found also to be associated with negative symptom response in the previous analysis.

A further study of the CATIE sample employed a theoretical model-based approach ${ }^{54}$ which found that several SNPs in the developmental gene EN1 (engrailed1) are associated with antipsychotic response. This study used data sets for schizophrenia risk genes and for mouse SNPs affecting prepulse inhibition of the startle reflex, a physiological effect which is consistently deficient in schizophrenia and reversed by antipsychotic drug treatment, to generate candidates for study in the CATIE database, of which only EN1 was found to be significant.
There have been other approaches using such unbiased independent methods to select candidate genes. Homer-1, a gene associated with glutamatergic transmission and identified as a candidate from animal studies of gene expression following haloperidol administration, shows SNP associations with response to treatment. ${ }^{55}$ An equivalent approach ${ }^{56}$ investigated changes in gene expression following risperidone administration to mice which were compared with findings from a GWAS of response to risperidone treatment. This identified several novel candidates, of which PDE-7 was found to have association both with disease, internally replicated, and with treatment response. Unfortunately, despite the apparent validity of these two approaches, there appears to be little consistency between them. Such criticism, to which much of the pharmacogenetic literature is susceptible, can always be countered by highlighting the differences between study samples in ethnicity, drug treatment and other such factors, but it remains a problem for the generalizability of any findings.

Iloperidone, an antipsychotic that was recently approved in the USA, underwent substantial pharmacogenetic study during its phase III trials. One investigation involved a GWAS that identified six SNPs in six genes associated with drug treatment respons $^{57}$; this data was re-analaysed in a retrospective assessment to identify response-dependent genetic subgroups of patients. ${ }^{58}$ How specific these findings are to iloperidone remains unclear; these authors report that the six SNPs identified did not significantly associate with ziprasidone response, although another group observed that two of the genes (XKR4 and GRIA4) were also associated with risperidone response..$^{59}$

\section{CONCLUSIONS}

For more than the past decade much effort has been spent in attempting to determine the genetic predictors of the effects of antipsychotic drugs, particularly in their positive effects on symptom response. It is clear that, despite this effort, identification of the major genetic contributors to the consequences of antipsychotic drug treatment still eludes us. There is a striking paucity of consistently reproducible findings in the pharmacogenetic studies reported. There are many reasons for this. One particularly important factor is that many studies are underpowered to identify what are often relatively small effects; this will inevitably introduce variability of results between studies. Other factors include differences in sample ethnicity, with the inevitable differences in genetic make-up between different ethnic samples. Different drug treatments may be associated with different pharmacogenetic influences, although it is important to note that, contrary to some suggestions in the literature, there is so far little evidence for truly 
drug-specific genetic associations. Other differences between samples may introduce inconsistencies; the response to treatment in first-episode and previously drug naïve patients may well differ in underlying pharmacological mechanisms from equivalent effects in patients with a chronic treatment history, resulting in different pharmacogenetic associations. Furthermore the clinical phenotypes measured may often be complex and multifactorial, composed of several physiological responses under different genetic control mechanisms, of which the negative and positive syndromes provide just one example. It should of course be remembered that symptom response to drug treatment is inevitably dependent on treatment adherence, and thus factors influencing compliance, such as unwanted side effects, will also be important in determining good response. Genetic factors also influence the emergence of adverse drug effects, and thus pharmacogenetic associations relating to the side effects of antipsychotic treatment, which have not been reviewed here, may indirectly contribute to the pharmacogenetic factors influencing symptom response.

Future work will need to overcome these many limitations and discrepancies reported in the current literature. There is need for a greater recognition of the potential importance of gene-gene interactions and, as is increasingly apparent in understanding disease pathogenesis, gene-environment interactions in understanding properly the risk factors contributing to poor response to antipsychotic treatment.

Nevertheless, the pharmacogenetics of antipsychotic drugs has progressed enormously, and new findings are beginning to take us towards a better understanding of the mechanisms underlying the effects of these drugs. As the technology develops and genotyping of large numbers of SNPs in large samples becomes cheaper and more accessible, findings from further GWAS studies will, we hope, converge to give us consistent results. Identifying such results will open up opportunities for predictive genetic testing, once their validity and, importantly, utility in the clinic are established.

\section{REFERENCES}

1. Cipriani A, Barbui C, Salanti G, Rendell J, Brown R, Stockton S, et al. Comparative efficacy and acceptability of antimanic drugs in acute mania: a multiple-treatments meta-analysis. Lancet 2011;378:1306-1315.

2. Vojvoda D, Grimmell K, Sernyak M, Mazure CM. Monozygotic twins concordant for response to clozapine. Lancet 1996;347:61.

3. Mata I, Madoz V, Arranz MJ, Sham P, Murray RM. Olanzapine: concordant response in monozygotic twins with schizophrenia. Br J Psychiatry 2001;178:86

4. Reynolds GP. The impact of pharmacogenetics on the development and use of antipsychotic drugs. Drug Discov Today 2007;12:953-959.

5. Lieberman JA, Stroup TS, McEvoy JP, Swartz MS, Rosenheck RA, Perkins DO, et al. Effectiveness of antipsychotic drugs in patients with chronic schizophrenia. N Engl J Med 2005;353:1209-1223.

6. Neill JC, Barnes S, Cook S, Grayson B, Idris NF, McLean SL, et al. Animal models of cognitive dysfunction and negative symptoms of schizo- phrenia: focus on NMDA receptor antagonism. Pharmacol Ther 2010; 128:419-432.

7. Meltzer HY, Massey BW. The role of serotonin receptors in the action of atypical antipsychotic drugs. Curr Opin Pharmacol 2011;11:59-67.

8. Reynolds GP, Templeman LA, Godlewska BR. Pharmacogenetics of schizophrenia. Expert Opin Pharmacother 2006;7:1429-1440.

9. Malhotra AK, Murphy GM Jr, Kennedy JL. Pharmacogenetics of psychotropic drug response. Am J Psychiatry 2004;161:780-796.

10. Zhang JP, Lencz T, Malhotra AK. D2 receptor genetic variation and clinical response to antipsychotic drug treatment: a meta-analysis. Am J Psychiatry 2010;167:763-772.

11. Hwang R, Zai C, Tiwari A, Muller DJ, Arranz MJ, Morris AG, et al. Effect of dopamine D3 receptor gene polymorphisms and clozapine treatment response: exploratory analysis of nine polymorphisms and meta-analysis of the Ser9Gly variant. Pharmacogenomics J 2010;10: 200-218.

12. Xuan J, Zhao X, He G, Yu L, Wang L, Tang W, et al. Effects of the dopamine $\mathrm{D} 3$ receptor (DRD3) gene polymorphisms on risperidone response: a pharmacogenetic study. Neuropsychopharmacology 2008;33: 305-311.

13. Xu MQ, St Clair D, Feng GY, Lin ZG, He G, Li X, et al. BDNF gene is a genetic risk factor for schizophrenia and is related to the chlorpromazine-induced extrapyramidal syndrome in the Chinese population. Pharmacogenet Genomics 2008;18:449-457.

14. Zhang A, Xing Q, Wang L, Du J, Yu L, Lin Z, et al. Dopamine transporter polymorphisms and risperidone response in Chinese schizophrenia patients: an association study. Pharmacogenomics 2007;8:1337-1345.

15. Serretti A, Drago A, De Ronchi D. HTR2A gene variants and psychiatric disorders: a review of current literature and selection of SNPs for future studies. Curr Med Chem 2007;14:2053-2069.

16. Benmessaoud D, Hamdani N, Boni C, Ramoz N, Hamon M, Kacha F, et al. Excess of transmission of the $\mathrm{G}$ allele of the $-1438 \mathrm{~A} / \mathrm{G}$ polymorphism of the 5-HT2A receptor gene in patients with schizophrenia responsive to antipsychotics. BMC Psychiatry 2008;8:40.

17. Lesch KP, Bengel D, Heils A, Sabol SZ, Greenberg BD, Petri S, et al. Association of anxiety-related traits with a polymorphism in the serotonin transporter gene regulatory region. Science 1996;274:1527-1531.

18. Dolzan V, Serretti A, Mandelli L, Koprivsek J, Kastelic M, Plesnicar BK. Acute antipyschotic efficacy and side effects in schizophrenia: association with serotonin transporter promoter genotypes. Prog Neuropsychopharmacol Biol Psychiatry 2008;32:1562-1566.

19. Wang L, Yu L, He G, Zhang J, Zhang AP, Du J, et al. Response of risperidone treatment may be associated with polymorphisms of HTT gene in Chinese schizophrenia patients. Neurosci Lett 2007;414:1-4.

20. Lee HY, Kim DJ, Lee HJ, Choi JE, Kim YK. No association of serotonin transporter polymorphism (5-HTTVNTR and 5-HTTLPR) with characteristics and treatment response to atypical antipsychotic agents in schizophrenic patients. Prog Neuropsychopharmacol Biol Psychiatry 2009;33:276-280.

21. Mossner R, Schuhmacher A, Kuhn KU, Cvetanovska G, Rujescu D, Zill $\mathrm{P}$, et al. Functional serotonin $1 \mathrm{~A}$ receptor variant influences treatment response to atypical antipsychotics in schizophrenia. Pharmacogenet Genomics 2009;19:91-94.

22. Reynolds GP, Arranz B, Templeman LA, Fertuzinhos S, San L. Effect of 5-HT1A receptor gene polymorphism on negative and depressive symptom response to antipsychotic treatment of drug-naive psychotic patients. Am J Psychiatry 2006;163:1826-1829.

23. Wang L, Fang C, Zhang A, Du J, Yu L, Ma J, et al. The --1019 C/G polymorphism of the 5-HT(1)A receptor gene is associated with negative symptom response to risperidone treatment in schizophrenia patients. J Psychopharmacol 2008;22:904-909.

24. Hu XZ, Lipsky RH, Zhu G, Akhtar LA, Taubman J, Greenberg BD, et al. Serotonin transporter promoter gain-of-function genotypes are linked to obsessive-compulsive disorder. Am J Hum Genet 2006;78:815-826.

25. Lemonde S, Turecki G, Bakish D, Du L, Hrdina PD, Bown CD, et al. 
Impaired repression at a 5-hydroxytryptamine $1 \mathrm{~A}$ receptor gene polymorphism associated with major depression and suicide. J Neurosci 2003;23:8788-8799.

26. Vazquez-Bourgon J, Arranz MJ, Mata I, Pelayo-Teran JM, Perez-Iglesias R, Medina-Gonzalez L, et al. Serotonin transporter polymorphisms and early response to antipsychotic treatment in first episode of psychosis. Psychiatry Res 2010;175:189-194.

27. Adams DH, Close S, Farmen M, Downing AM, Breier A, Houston JP. Dopamine receptor D3 genotype association with greater acute positive symptom remission with olanzapine therapy in predominately caucasian patients with chronic schizophrenia or schizoaffective disorder. Hum Psychopharmacol 2008;23:267-274.

28. Meary A, Brousse G, Jamain S, Schmitt A, Szoke A, Schurhoff F, et al. Pharmacogenetic study of atypical antipsychotic drug response: involvement of the norepinephrine transporter gene. Am J Med Genet B Neuropsychiatr Genet 2008;147B:491-494.

29. Schuhmacher A, Mossner R, Quednow BB, Kuhn KU, Wagner M, Cvetanovska G, et al. Influence of 5-HT3 receptor subunit genes HTR3A, HTR3B, HTR3C, HTR3D and HTR3E on treatment response to antipsychotics in schizophrenia. Pharmacogenet Genomics 2009;19:843851.

30. Silver H. Selective serotonin re-uptake inhibitor augmentation in the treatment of negative symptoms of schizophrenia. Expert Opin Pharmacother 2004;5:2053-2058.

31. Bertolino A, Caforio G, Blasi G, Rampino A, Nardini M, Weinberger DR, et al. COMT Val158Met polymorphism predicts negative symptoms response to treatment with olanzapine in schizophrenia. Schizophr Res 2007;95:253-255.

32. Fijal BA, Kinon BJ, Kapur S, Stauffer VL, Conley RR, Jamal HH, et al. Candidate-gene association analysis of response to risperidone in African-American and white patients with schizophrenia. Pharmacogenomics J 2009;9:311-318.

33. Weickert TW, Goldberg TE, Mishara A, Apud JA, Kolachana BS, Egan MF, et al. Catechol-O-methyltransferase val108/158met genotype predicts working memory response to antipsychotic medications. Biol Psychiatry 2004;56:677-682.

34. Bishop JR, Ellingrod VL, Moline J, Miller D. Association between the polymorphic GRM3 gene and negative symptom improvement during olanzapine treatment. Schizophr Res 2005;77:253-260.

35. Bishop JR, Miller DD, Ellingrod VL, Holman T. Association between type-three metabotropic glutamate receptor gene (GRM3) variants and symptom presentation in treatment refractory schizophrenia. Hum Psychopharmacol 2011. in press.

36. Zuo L, Luo X, Krystal JH, Cramer J, Charney DS, Gelernter J. The efficacies of clozapine and haloperidol in refractory schizophrenia are related to DTNBP1 variation. Pharmacogenet Genomics 2009;19:437-446.

37. Mossner R, Schuhmacher A, Wagner M, Lennertz L, Steinbrecher A, Quednow BB, et al. The schizophrenia risk gene ZNF804A influences the antipsychotic response of positive schizophrenia symptoms. Eur Arch Psychiatry Clin Neurosci 2011. in press.

38. Lemonde S, Du L, Bakish D, Hrdina P, Albert PR. Association of the C (-1019)G 5-HT1A functional promoter polymorphism with antidepressant response. Int J Neuropsychopharmacol 2004;7:501-506.

39. Goldberg TE, Kotov R, Lee AT, Gregersen PK, Lencz T, Bromet E, et al. The serotonin transporter gene and disease modification in psychosis: evidence for systematic differences in allelic directionality at the 5-HTTLPR locus. Schizophr Res 2009;111:103-108.

40. Tollefson GD, Andersen SW, Tran PV. The course of depressive symptoms in predicting relapse in schizophrenia: a double-blind, randomized comparison of olanzapine and risperidone. Biol Psychiatry 1999;46: 365-373.

41. Reynolds GP. Receptor mechanisms in the treatment of schizophrenia.
J Psychopharmacol 2004;18:340-345.

42. Arranz MJ, Munro J, Birkett J, Bolonna A, Mancama D, Sodhi M, et al. Pharmacogenetic prediction of clozapine response. Lancet 2000;355: 1615-1616.

43. Parsons MJ, D'Souza UM, Arranz MJ, Kerwin RW, Makoff AJ. The $-1438 \mathrm{~A} / \mathrm{G}$ polymorphism in the 5-hydroxytryptamine type $2 \mathrm{~A}$ receptor gene affects promoter activity. Biol Psychiatry 2004;56:406-410.

44. Arranz MJ, Rivera M, Munro JC. Pharmacogenetics of response to antipsychotics in patients with schizophrenia. CNS Drugs 2011;25:933-969.

45. Zhang JP, Malhotra AK. Pharmacogenetics and antipsychotics: therapeutic efficacy and side effects prediction. Expert Opin Drug Metab Toxicol 2011;7:9-37.

46. Muller DJ, De Luca V, Sicard T, King N, Hwang R, Volavka J, et al. Suggestive association between the C825T polymorphism of the G-protein beta3 subunit gene (GNB3) and clinical improvement with antipsychotics in schizophrenia. Eur Neuropsychopharmacol 2005;15:525-531.

47. Anttila S, Kampman O, Illi A, Rontu R, Lehtimaki T, Leinonen E. Association between 5-HT2A, TPH1 and GNB3 genotypes and response to typical neuroleptics: a serotonergic approach. BMC Psychiatry 2007; $7: 22$.

48. Kohlrausch FB, Salatino-Oliveira A, Gama CS, Lobato MI, Belmontede-Abreu P, Hutz MH. G-protein gene $825 \mathrm{C}>\mathrm{T}$ polymorphism is associated with response to clozapine in Brazilian schizophrenics. Pharmacogenomics 2008;9:1429-1436.

49. Need AC, Keefe RS, Ge D, Grossman I, Dickson S, McEvoy JP, et al. Pharmacogenetics of antipsychotic response in the CATIE trial: a candidate gene analysis. Eur J Hum Genet 2009;17:946-957.

50. Kantrowitz JT, Javitt DC. N-methyl-d-aspartate (NMDA) receptor dysfunction or dysregulation: the final common pathway on the road to schizophrenia? Brain Res Bull 2010;83:108-121.

51. Tamminga CA. The neurobiology of cognition in schizophrenia. J Clin Psychiatry 2006;67(Suppl 9):9-13.

52. McClay JL, Adkins DE, Aberg K, Stroup S, Perkins DO, Vladimirov VI, et al. Genome-wide pharmacogenomic analysis of response to treatment with antipsychotics. Mol Psychiatry 2011;16:76-85.

53. McClay JL, Adkins DE, Aberg K, Bukszar J, Khachane AN, Keefe RS, et al. Genome-wide pharmacogenomic study of neurocognition as an indicator of antipsychotic treatment response in schizophrenia. Neuropsychopharmacology 2011;36:616-626.

54. Webb BT, Sullivan PF, Skelly T, van den Oord EJ. Model-based gene selection shows engrailed 1 is associated with antipsychotic response. Pharmacogenet Genomics 2008;18:751-759.

55. Spellmann I, Rujescu D, Musil R, Mayr A, Giegling I, Genius J, et al. Homer-1 polymorphisms are associated with psychopathology and response to treatment in schizophrenic patients. J Psychiatr Res 2011;45: 234-241.

56. Ikeda M, Tomita Y, Mouri A, Koga M, Okochi T, Yoshimura R, et al. Identification of novel candidate genes for treatment response to risperidone and susceptibility for schizophrenia: integrated analysis among pharmacogenomics, mouse expression, and genetic case-control association approaches. Biol Psychiatry 2010;67:263-269.

57. Lavedan C, Licamele L, Volpi S, Hamilton J, Heaton C, Mack K, et al. Association of the NPAS3 gene and five other loci with response to the antipsychotic iloperidone identified in a whole genome association study. Mol Psychiatry 2009;14:804-819.

58. Volpi S, Potkin SG, Malhotra AK, Licamele L, Lavedan C. Applicability of a genetic signature for enhanced iloperidone efficacy in the treatment of schizophrenia. J Clin Psychiatry 2009;70:801-809.

59. Fijal BA, Stauffer VL, Kinon BJ, Conley RR, Hoffmann VP, Witte MM, et al. Analysis of gene variants previously associated with iloperidone response in patients with schizophrenia who are treated with risperidone. J Clin Psychiatry 2011. in press. 